\title{
DISTRIBUTION OF COMBAT CAPABILITIES ON OBJECTIVES BY USING A TRANSPORT PROBLEM
}

\author{
Alexandru BABOȘ, Alina-Mihaela BABOȘ \\ "Nicolae Bălcescu" Land Forces Academy of Sibiu, Romania \\ babos.alexandru@yahoo.com, alina_babos_24@yahoo.com
}

\begin{abstract}
The transport problem finds its application in situations where the upper echelons must draw up an optimal plan of resources allocation for combat capabilities on objectives. In order to achieve more reliable results for the real problem, the data needed to formulate the mathematical model are extracted from an order of operations. This paper presents the optimization of military action, showing how to solve a practical problem using the transportation problem.
\end{abstract}

Keywords: transport, resources, operations

\section{Introduction}

Emerged from military needs, the operational research essentially deals with the decision optimization by using mathematical modeling and data provided by an action generically called operation.

The transport problem finds its applicability in situations where the upper echelons have to draw up an optimal plan for the distribution of combat or fire capabilities on the targets. For the results to be as reliable as possible for the real problem, the data required to formulate the mathematical model are gathered from a realistic scenario.

should be divided into sections, each with a

\section{Problem formulation}

We need information about the tactical situation information, mission statement, execution, necessary logistic support, and command and communications instructions. From these sets of information, we extract only those necessary to translate the problem into practice into a mathematical model that once solved will provide the optimal solution.

DOI: $10.1515 / \mathrm{kbo}-2017-0002$

(C) 2017. This work is licensed under the Creative Commons Attribution-NonCommercial-NoDerivatives 3.0 License.
The information about the situation is generally related to the forces of the enemy and our own forces, namely their location and the main courses of action.

So, we suppose to have 3 mechanized infantry battalions found in a defense situation to stop the enemy offensive on their directions of attack. With the support of the upper echelon and effectively using the technical-tactical characteristics of the weapons, exploiting on the natural properties of the battle field and performing numerous offensive retaliation, the subunits managed to stop the enemy offensive.

The execution instructions are divided into three categories: intent, design and coordination instructions. In this case the superior echelon intends to make a series of trips on three main directions of attack. The embarquement will take place on three aerodromes, on the available airplanes. After landing, the permanent passes will be investigated from the immediate vicinity, then the enemy device will be searched, the officers will be captured, the armored vehicles and the communications points destroyed. 
Ultimately, the destruction of the enemy command point is attempted. For better efficiency, mixed teams of the three units will be created after landing.

\section{Preparing the mathematical model-Solving the problem}

In order to prepare the mathematical model, the following notations will be made:

$$
a_{i}(\mathrm{i}=1,2, \ldots, \mathrm{m}) \text {, }
$$

The number of available fighters prepared for boarding in each of the three units $A_{i}$;

$$
o_{j}(j=1,2, \ldots, n) \text {, }
$$

The number of fighters to be parachuted on each enemy target in the landing districts to cover the entire area of operations;

$g_{j}$, The number of troops that can be transported by airplanes from the aerodrome $A_{i}$ to objective $O_{j}$. Into the calculation of this data set were taken into account the standard aircraft loading capacity, the distance from the aerodrome to the target, the flight height, the flight speed and the weight of the battle load, etc; $x_{i j}$, The number of troops that can be transported by airplanes from the aerodrome $A_{i}$ to objective $O_{j}$ during the whole operation;

$y_{i j}$, Number of flights / airplane from aerodrome $A_{i}$ to objective $O_{j}$ during the whole operation.

In order to make the optimal flight chart, it is therefore necessary to determine the values $y_{i j}$ so that:

- Each aerodrome will send all available personnel $\left(a_{i}\right)$ to maximize the chances of success of the operation;

- To send to each objective the number of fighters $\left(o_{j}\right)$ which was predicted to cover the whole area of operations in an efficient manner;

- The whole operation must be carried out with a limited number of aircraft and with a minimum number of flights.

The mathematical model of a problem of

\begin{tabular}{|c|c|c|c|c|}
\hline$A_{i} / O_{j}$ & $O_{1}$ & $\mathrm{O}_{2}$ & $\mathrm{O}_{3}$ & $a_{i}$ \\
\hline$A_{1}$ & $x_{11}{ }^{12}$ & $x_{12}$ & $\begin{array}{ll} & 8 \\
x_{13} & \end{array}$ & 120 \\
\hline$A_{2}$ & $\begin{array}{ll} & 16 \\
x_{21} & \end{array}$ & $x_{22}$ & $\begin{array}{ll} & 12 \\
x_{23} & \\
\end{array}$ & 100 \\
\hline$A_{3}$ & $\begin{array}{ll} & 35 \\
x_{31}\end{array}$ & $x_{32}$ & $x_{33} \quad 46$ & 175 \\
\hline$o_{j}$ & 134 & 156 & 105 & 395 \\
\hline
\end{tabular}
this kind will look like this

Figure1: Problems mathematical model

The numbers above the diagonal are the number of fighters that can be transported by each of the three aircrafts.

Optimized function whose minimum is sought is therefore:

$$
F=\sum_{i=1}^{3} \sum_{j=1}^{5} y_{i j}=\sum_{i=1}^{3} \sum_{j=1}^{5} \frac{x_{i j}}{g_{i j}}
$$

In order for this minimum to be realized, the $x_{i j}$ values must be determined corresponding to the highest values of $g_{i j}$. For this purpose, the maximum matrix element method is applied because:

$\min . \sum_{i=1}^{3} \sum_{j=1}^{5} \frac{x_{i j}}{g_{i j}}=\max . \sum_{i=1}^{3} \sum_{j=1}^{5} x_{i j} \cdot g_{i j}$.

The following basic initial solution will be obtained which contains the number of soldiers assigned to each goal: 


\begin{tabular}{|c|c|c|}
\hline 34 & 86 & 0 \\
\hline 100 & 0 & 0 \\
\hline 0 & 70 & 105 \\
\hline
\end{tabular}

Figure 2: Initial basis solution

Starting from this solution, the end result is optimized. We check whether the solution is degenerate or not with the formula $m+n$ $1=\mathrm{nr}$. values $x_{i j}>0$ so: $3+3-1=5$ bigger values than $0(34,86,100,70$, and 105) it results that the solution is non-generated, so the distributive method can be directly applied.
The scope function is calculated as follows: $F_{\text {min }}=34 \div 12+86 \div 10+0 \div 8+100 \div 16+0 \div 15+0$ $\div 12+0 \div 35+70 \div 40+105 \div 46=3+9+7++2+3=$ 24 flights.

The solution obtained is passed to the following table (bold values are the number of fighters to be transported to each goal in order to be optimized):

\begin{tabular}{|c|c|c|c|c|}
\hline$A_{i} / O_{j}$ & $O_{1}$ & $\mathrm{O}_{2}$ & $O_{3}$ & $a_{i}$ \\
\hline$A_{1}$ & $34 \quad 12$ & $\begin{array}{ll}86 & 10\end{array}$ & $\begin{array}{ll} & 8 \\
0 & \end{array}$ & 1200 \\
\hline$A_{2}$ & $\mathbf{1 0 0} \quad 16$ & $\begin{array}{ll} & 15 \\
\mathbf{0} & \end{array}$ & $\begin{array}{ll} & 12 \\
\end{array}$ & 1000 \\
\hline$A_{3}$ & $\begin{array}{ll} & 35 \\
0\end{array}$ & $\begin{array}{ll}70 & 40\end{array}$ & 105 & 175700 \\
\hline$o_{j}$ & 134340 & 156860 & 1050 & 395 \\
\hline
\end{tabular}

Figure 3: Initial basis solution and intermediate calculations

We check whether the solution obtained is the optimal one by calculating the differences $\Delta_{i j}$ so we obtain:

$$
\Delta_{13}=8-10+40-46=
$$

$\mathbf{- 8}$ (negative difference)

$$
\begin{gathered}
\Delta_{22}=15-16+12-10=1 \\
\Delta_{23}=12-16+12-10=-2
\end{gathered}
$$

(negative difference)

$$
\Delta_{31}=35-40+10-12=
$$

-7 (negative difference)

It follows the correction of the negative differences, so the differences $\Delta_{13}=-8$ și $\Delta_{23}$ $=-23$. Because not all the differences $\Delta_{i j}$ are positive it means that the initial basis solution is not the optimal one.

\begin{tabular}{|c|c|c|c|c|}
\hline$A_{i} / O_{j}$ & $O_{1}$ & $\mathrm{O}_{2}$ & $O_{3}$ & $a_{i}$ \\
\hline$A_{1}$ & $\begin{array}{l}34 \\
-19\end{array}$ & $\begin{array}{l}86 \\
-86\end{array}$ & $\begin{array}{l}\mathbf{0} \\
+105\end{array}$ & 120 \\
\hline$A_{2}$ & 100 & $\mathbf{0}$ & 0 & 100 \\
\hline$A_{3}$ & $\begin{array}{l}\mathbf{0} \\
+19\end{array}$ & $\begin{array}{l}70 \\
+86\end{array}$ & $\begin{array}{l}\mathbf{1 0 5} \\
\quad-105\end{array}$ & 175 \\
\hline$o_{j}$ & 134 & 156 & 105 & 395 \\
\hline
\end{tabular}

The negative difference was given by the corresponding box $\Delta_{13}=-8$, so the cycle will form from the box as follows:

Figure 4: First formed cycle and intermediate calculations 
By doing similar to $\Delta_{23}$ and $\Delta_{31}$ we eliminate the negative differences and come to the solution:

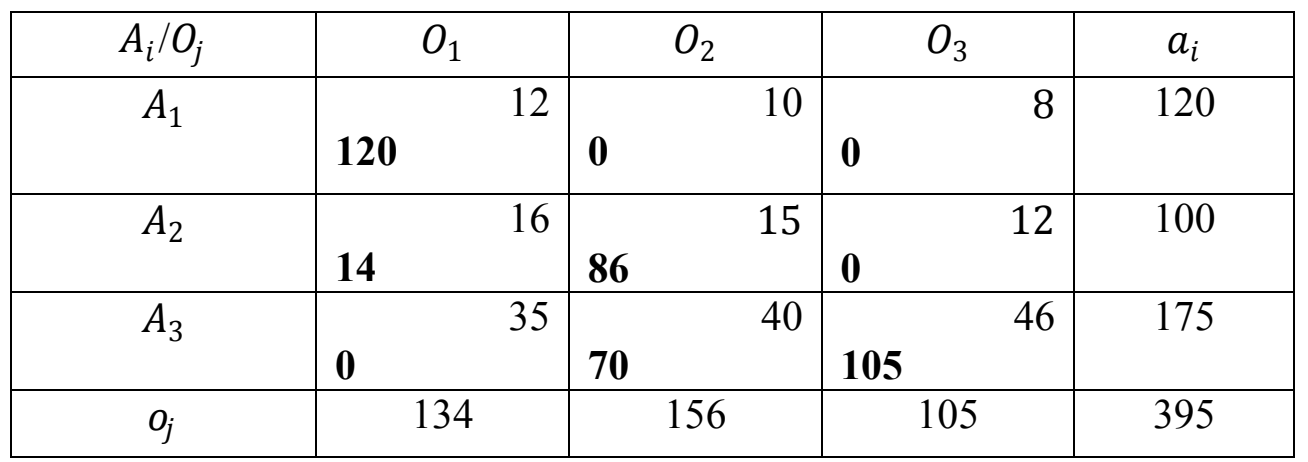

Figure 5: Final solution problem

The new function is:

$F_{\min } \sum_{i=1}^{3} \sum_{j=1}^{5} \frac{x_{i j}}{g_{i j}}=\frac{120}{12}+\frac{0}{10}+\frac{0}{8}+\frac{14}{16}+$ $\frac{86}{15}+\frac{0}{12}+\frac{0}{35}+\frac{70}{40}+\frac{105}{46}=10+1+62+3=22$

flights (transport), $22<24$ so it's easy to see that the new solution is better than the previous one.

To eliminate as far as possible human computational errors, we check whether the solution obtained is the optimal one with The Scientist Manager.

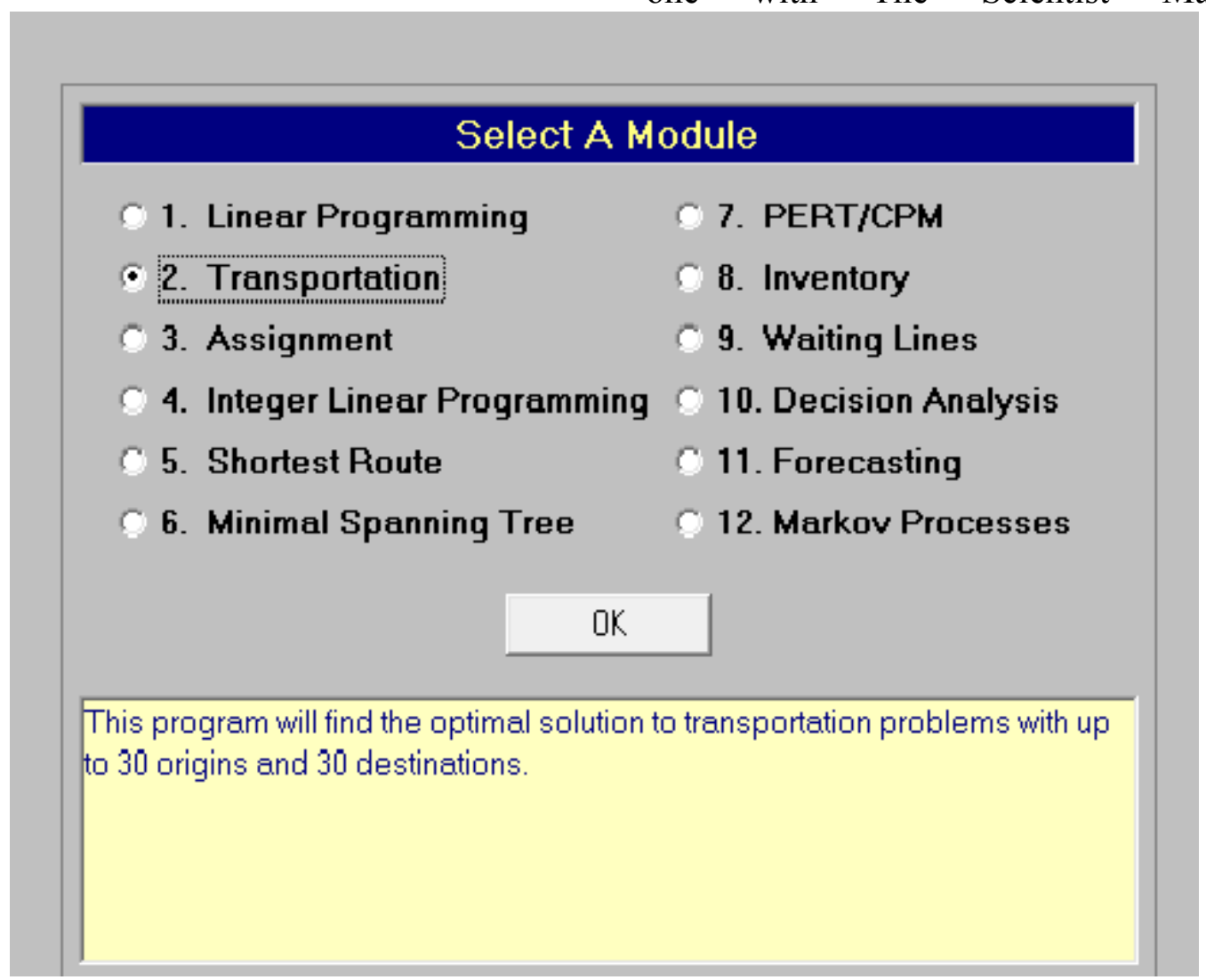

Figure 6: Application interface (main menu)

We enter the necessary data into the application (the number of sources and origins, respectively aerodromes and objectives in this case): 


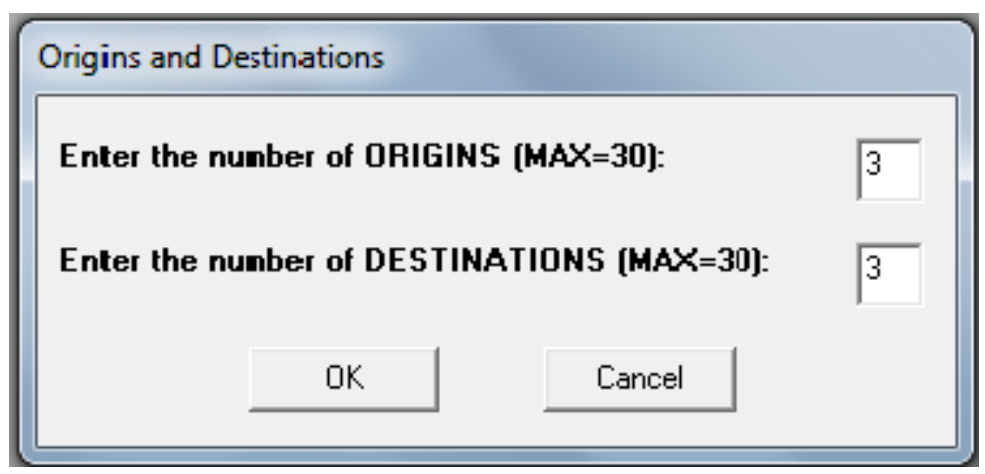

Figure 7: Variable numbers settings

The initial values are added $a_{i}, o_{j}$ și $g_{j}$ as

follows :

\begin{tabular}{|c|c|c|c|c|}
\hline \multicolumn{4}{|c|}{ Destination } & \\
\hline Origin & 1 & \begin{tabular}{l|l}
2 & 3
\end{tabular} & \multicolumn{2}{|r|}{ Supply } \\
\hline 1 & 12 & 10 & 8 & 120 \\
\hline 2 & 16 & 15 & 12 & 100 \\
\hline 3 & 35 & 40 & 46 & 175 \\
\hline Demand & 134 & 156 & 105 & $=======$ \\
\hline
\end{tabular}

Figure 8: Initial data insertion

When selecting the type of the objective function, the maximization option is chosen because we set it at first:

$$
\min . \sum_{i=1}^{3} \sum_{j=1}^{5} \frac{x_{i j}}{g_{i j}}=\max . \sum_{i=1}^{3} \sum_{j=1}^{5} x_{i j} \cdot g_{i j} \text {. }
$$

After running the program we get the following solution which is coincident with the original:

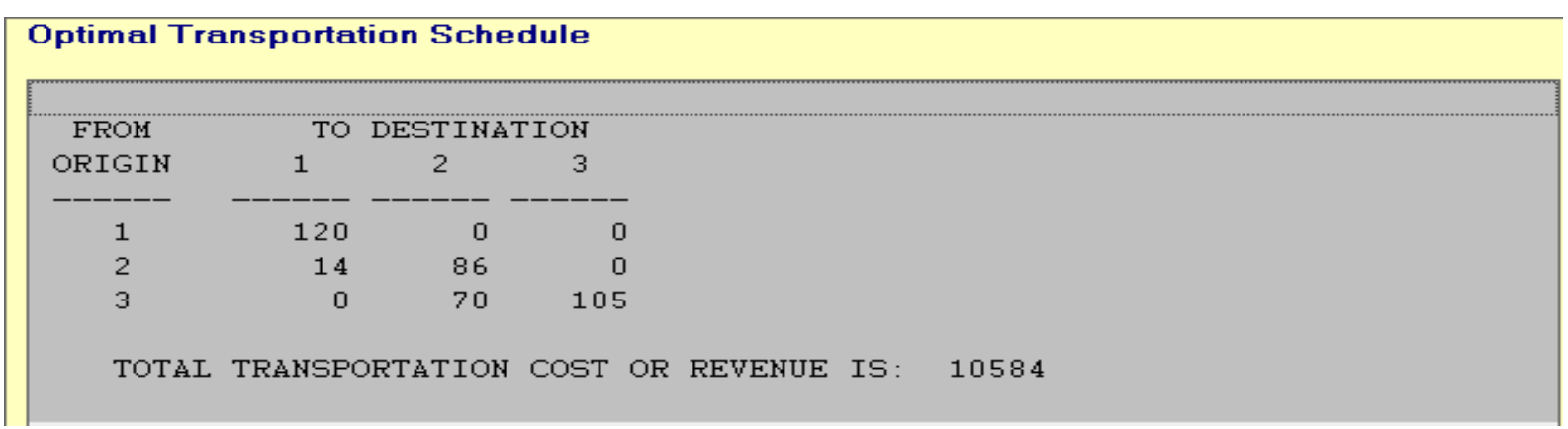

Figure 9: Final result

By making the divisions $\left(x_{i j} \div g_{i j}\right)$, we will then get the number of flights / airplane from each of the three aerodromes at each of the 3 objectives. The optimal flight schedule is shown in the following table: 


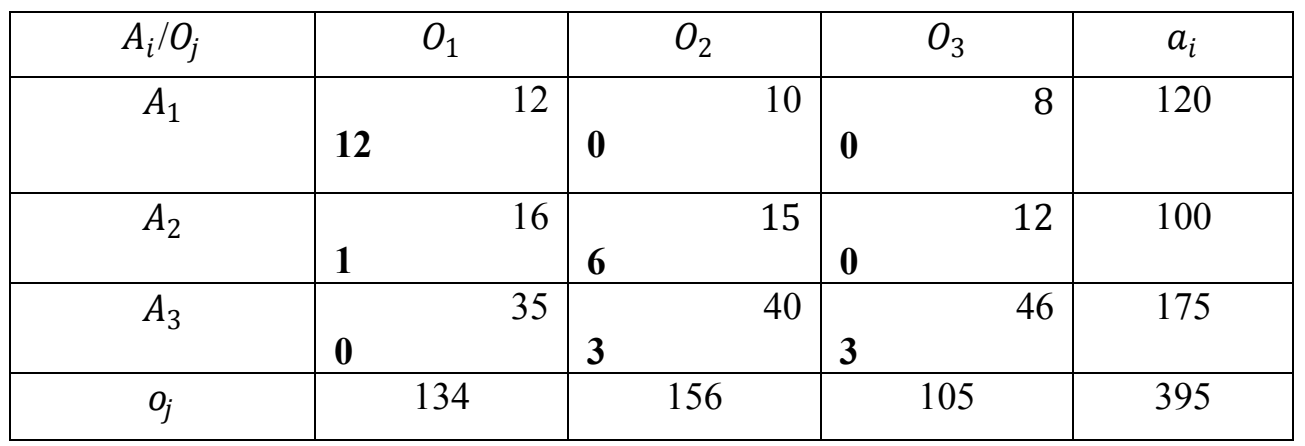

Figure 10: Optimal flights graph

If this plan is respected, the entire number of fighters required for the mission will be carried by air, with the foreseen restrictions on the number of available aircraft at a minimum cost and in the shortest possible time.

Another graph that leads to fewer transports under the given conditions cannot exist.
4. Conclusions

If these methods of operational research are accepted and applied in the decisionmaking process, they will only develop analytical thinking among the officers, and so they will be able to cope with the demands of the modern battlefield, making more and more rational decisions.

\section{References}

[1] Dumitru, V., Rugină, N., Stoian, I., Modelareamatematicăaacțiunilormilitare, Bacău,Editura Diagonal, 2002.

[2] Grad, V., Stoian, I., Kovacs, E., Dumitru, V., Cercetareoperaționalăîndomeniulmilitar, București, EdituraSylvi, 2000.

[3] Hampu, A., Căruțașu, V., Cercetărioperaționale cu aplicațiiîndomeniulmilitar, Sibiu, EdituraUniversității Lucian Blaga, 1999.

[4] Maurice, K., Operational Research in War and Peace, Londra,Editura Imperial College Press, 2003. 